\title{
Employing Blended Learning Health Sciences \\ Graduates in Saudi Arabia: Community Preceptors' Evaluation of Interns
}

Bussma Bugis ( $\sim$ b.bugis@seu.edu.sa )

\section{Research}

Keywords: Blended Learning, Health Sciences, Internship, Professional Competencies, Saudi Arabia, Community Preceptor, Evaluation, Interns, Health Informatics, Public Health

Posted Date: May 11th, 2020

DOI: https://doi.org/10.21203/rs.3.rs-27276/v1

License: (c) (1) This work is licensed under a Creative Commons Attribution 4.0 International License.

Read Full License 


\section{Abstract}

Background Studies about internships are mostly done on the internship experiences of interns who received traditional face-to-face education, but limited studies were done on interns who studied under a blended learning educational style. Similarly, most studies on the professional competencies of health sciences graduates are done on the graduates of traditional schools. This study aims to describe the professional competencies of blended learning health sciences graduates through community preceptors' evaluations of interns in Saudi Arabia. Methods This study is a secondary analysis of existing data that are available from the College of Health Sciences at the Saudi Electronic University. The study population consists of 96 community preceptors who evaluated 90 health sciences undergraduate interns during the last six months of 2019. Results Data analysis is a descriptive method that provides simple statistics related to evaluation variables. The study tested the technical competencies, nontechnical competencies, and employment perceptions of interns. The mean scores for technical and nontechnical competencies represent positive evaluations of health sciences interns who graduated from undergraduate programs. The standard deviations indicate that most responses are fairly close to the mean scores. The modes for all competences are excellent. Of the 96 evaluations, more than 90\% answered "YES" to hiring blended learning health sciences graduates. Conclusions From the perception of community preceptors, blended learning graduates who majored in health sciences are competent and well prepared to be employed in the health sector in Saudi Arabia and globally.

\section{Background}

In Saudi Arabia, the Ministry of Health $(\mathrm{MOH})$ is the official governmental body that governs the health sector and leads the transformational activities related to the Saudi 2030 Vision which was released in $2016(1,2)$. As a result, the Healthcare Transformation Strategy identifies the challenges and issues that are facing the healthcare sector, was released by the $\mathrm{MOH}$. Some of these challenges are related workforce development, productivity, capacity and capability (3).

Across the health sector in Saudi Arabia, approximately 710,000 healthcare professionals are needed by 2030 , which is a 36,000 increase in the labor demand for healthcare professionals over the number that was working during 2019 in the sector (4). Preparing the labor market to meet the demand requires an effective coordination of different sectors, especially between higher education and employers. Health employers heavily rely on qualifications, knowledge, skills, personality and ethics in the process of healthcare hiring which graduates are expected to have (5). Proper training and development of the labor market along with coercing qualified talents to choose the healthcare sector as their career are among the objectives needed to achieve the proper transform of the healthcare sector (6).

Studies about internships are mostly done on the internship experiences of interns who received traditional face-to-face education, but limited studies were done on interns who received blended learning education. Similarly, most studies of the professional competencies of health sciences graduates are done on graduates of traditional schools. The purpose of this paper is to describe the professional 
competencies of blended learning health sciences graduates through community preceptors' evaluations of interns in Saudi Arabia.

Competency is described as "a set of success factors that include the key attributes required for excellent performance in a particular role" (7). Professional competence can be divided into two main views: the first view is about a set of essential characteristics or qualifications that individuals must have to perform tasks, and, the second view is about the production and execution of work (8). Health professional competencies include interpersonal health support, community health support, and administrative competencies (9). Interpersonal health support competencies include individual characteristics, communication and experiences; community health support competencies consist of role expectations, responsibilities, teamwork, skills and knowledge; and administrative competencies include organizing, planning, and monitoring (9-11). A fourth competency is identified as nontechnical competencies, which are related to but not limited to adaptability, motivations, cooperation, ethics, and creativity $(11,12)$.

Knowledge, skills and experience are related to personal and organizational factors positively associated with the accumulative development of competencies (9). The knowledge and awareness of role expectations can be obtained through educational and academic institutions that offer academic degree programs and professional associations that offer professional continuing education courses. Training plays a major role in supplying and endowing health professionals with the required skills and experiences (9).

An international survey on internship quality that was conducted in 2011 mentioned that formal education alone is not enough to allow a job seeker to access to the job market (13). The International Labour Office (ILO) described an internship as "a limited period of work experience with an employer usually lasting between a few weeks to one year but which is neither part of a regular employment relationship nor a formal apprenticeship" (14). Academic programs aim to provide students with opportunities where they can apply classroom knowledge to real-life settings. Generally, students have a positive view of internships as they gain a deeper understanding of their professions and develop their personal professional skills through internships $(5,15,16)$. On the other hand, employers' perceptions of student internships may vary due to different reasons such as the organization's size, the number of employees, being for-profit or nonprofit, and other reasons $(15,17)$. In Saudi Arabia, most health sciences related academic programs have internships as a part of their curriculum structures, which vary between different educational institutions since they vary in learning and educational styles and include the following: regularity, correspondence, distance learning, and blended learning (18).

Blended Learning in general is the interactive mixture of traditional teaching and electronic learning methods (19). There are three types of blended learning (BL): a combination of traditional face-to-face and online learning, a combination of different technologies, and a combination of different methodologies (20). Some Australian universities highlighted issues with medical students who received traditional education having limited skills regarding nontechnical engagements such as team work, creative thinking, self-regulation, and critical thinking. As a result, medical students were introduced to a 
blended learning program that aims to supply medical students with nontechnical skills via online discussion, digital evaluations, online case scenarios, and face-to-face activities. Interestingly, the program has become a fundamental program and developers were given incentives to continue their development (21). A Dutch study was conducted to study the perceptions of general practitioners (GP) trainers through blended learning interventions. GP trainers positively evaluated blended learning in both knowledge and practice (19). Again, very limited studies in the literature regarding the internships designed to bridge the gaps between educational and professional competences in health sciences were done on blended learning graduates. In this paper, we will describe community preceptors' evaluations of blended learning health sciences interns from the perspective of employers.

\section{Methods}

This study is a secondary analysis of existing data that aims to describe the professional competencies of blended learning health sciences graduates through community preceptors' evaluations of interns in Saudi Arabia. The existing data are available from the College of Health Sciences (CHS) at the Saudi Electronic University (SEU) which is currently the only Saudi governmental university that specializes in the blended learning method (22). Primary data were collected using an evaluation questionnaire as part of the normal practice activities related to the internship evaluation. The study population consists of 96 community preceptors who supervised and evaluated 90 health sciences undergraduate interns during the last six months of 2019, were each internship period is 3 months. Community preceptors were invited to complete the electronic evaluation questionnaire at the completion of the internship periods of the interns they supervised. Data related to the questionnaire are not publicly available. Therefore, the only data come from the 96 post-internship evaluations collected by the CHS at SEU.

\section{Results}

Data analysis is a descriptive method that provides simple statistics related to evaluation variables. Means, modes, standard deviations, and percentages are used to describe the study observations. The study was conducted at the CHS which offers two undergraduate programs: health informatics and public health (22). All 90 interns did their internships in Saudi Arabia at one of 47 internship sites, which vary between the public sector, private sector, and other agencies that offer health/medical services to their affiliated employees and their families. The distribution is illustrated in Table 1. Out of the 90 interns, $83.33 \%$ were from the health informatics program while the remaining $16.67 \%$ were from the public health major.

The preceptors' evaluations of interns' performance are presented in the following aspects: first are the technical competencies, which are measured through interpersonal health support, community health support, and administrative competencies; and second are nontechnical competencies. The results are shown in Table 2. Mean scores are derived to determine whether community preceptors have negative or positive evaluations of interns' performance during the internship period. 
Ninety-six community preceptors evaluated 90 health sciences undergraduate interns during the last six months of 2019. Out of the 96 evaluators, $84.375 \%$ evaluated interns from the health informatics program while the remaining $15.625 \%$ evaluated interns from the public health major.

The mean scores for the technical and nontechnical competencies represent positive evaluations of health sciences interns who graduated from blended learning undergraduate programs. The standard deviations are less than 1 , which indicate that most responses are fairly close to the mean scores, except for the "degree of independence" that had a SD above one, although it is still considered small. The modes for all competences are excellent, even for the lowest reported mean. Overall, preceptors' evaluations of the interns' overall performance are positive, and are in fact excellent.

Community preceptors were also asked if they would hire their interns at their affiliated organizations if they have the opportunity. This question was essential to measure employers' perceptions of health sciences graduates from a blended learning program since preceptors may represent an important view of their affiliated organizations. Of the 96 evaluations of both majors, more than $90 \%$ answered "YES" to hiring blended learning health sciences graduates while no observation was recorded for the negative answer. Figure 1 shows the evaluators' opinions regarding employing this specific group of interns.

\section{Discussion}

The findings imply that the competencies of blended learning health sciences graduates are perceived to be at an excellent level by different community preceptors, indicating that these graduates were supplemented with the essential knowledge, skills, and techniques of their majors. As a result, more than $90 \%$ of community preceptors would recommend hiring these interns at their affiliated organizations.

The study is limited since the study population is small, especially for the public health interns, which may cause an unbalanced analysis of both majors. In addition, the shortage of similar studies with different populations in the literature means that the researcher is unable to compare the professional competencies of health sciences graduates who graduated from blended learning undergraduate programs with others.

\section{Conclusions}

In this study, a secondary analysis of existing private date from SEU was done. The community preceptors' evaluations of health sciences interns who graduated from a blended learning undergraduate program were assessed. The study tested the technical competencies, nontechnical competencies, and the employment perceptions of interns. The findings of the study show that most community preceptors felt positively about the job competencies of the interns and most would hire interns if they have the opportunity. Overall, from community preceptors' perspective, blended learning graduates who majored in health sciences are competent and well prepared to be employed in the health sector in Saudi Arabia and 
globally. Future studies are needed to fill the gap in the literature regarding the professional competences of blended learning graduates.

\section{Abbreviations}

SEU: Saudi Electronic University, CHS: College of Health Sciences, BL: Blended Learning, MOH: Ministry of Health, and MOE: Ministry of Education

\section{Declarations}

\section{Ethics approval and consent to participate}

The study protocol has been reviewed and approved by the SEU Deanship of Scientific Research. The study was determined to be exempt from review by the SEU Research Ethics Committee as study \# SEUREC-CHS20104.

\section{Consent for Publication}

Not applicable

\section{Availability of data and materials}

The data that support the findings of this study are available from the College of Health Sciences at the Saudi Electronic University but restrictions apply to the availability of these data, which were used under license for the current study, and so are not publicly available. The data are, however, available from the authors upon reasonable request and with the permission of the College of Health Sciences at the Saudi Electronic University.

\section{Competing interests}

The authors declare that they have no competing interests.

\section{Funding}

None

\section{Authors' Contributions}

The author has designed the work, conducted the analysis, and drafted the work. The author has approved the submitted version.

\section{Acknowledgements}

The author wishes to thank all community preceptors for providing feedback on interns. The author also wishes to thank the College of Health Sciences of SEU for permitting the use of their existing data for 
research purposes.

\section{Author's information}

The author holds a DrPH degree in Health Services Organizations and MPA and BS degrees in Health Services Administration. Currently, she is an Assistant Professor at the Saudi Electronic University and the Vice Dean for Females Section at the College of Health Sciences.

\section{References}

1. MOH. Health Sector Governance

$\mathrm{MOH}$. Health Sector Governance. 2018 [updated Aug 15. Available from:

"https://www.moh.gov.sa/en/Ministry/vro/Governance/Pages/default.aspx".

2. Council US-SAB. Working in Saudi Arabia: A Labor Market Update. us.sabc.org; 2017.

3. MOH. Healthcare Transformation Strategy V3. Ministry of Health2019.

4. Al-Hanawi MK, Khan SA, Al-Borie HM. Healthcare human resource development in Saudi Arabia: emerging challenges and opportunities-a critical review. Public Health Rev. 2019;40:1.

5. Yaakob H, Ail KM, Radzi NF. The Effect of Internship on Job Performance: An Assessment of Student's Perception. International Journal of Scientific Engineering Research. 2018;9(7):378-82.

6. KSA. National Transformation Program Delivery Plan. Vision 2030 Kingdom of Saudi Arabia20182020.

7. Verma S, Paterson M, Medves J. Core Competencies for Health Care Professionals: What Medicine, Nursing, Occupational Therapy, and Physiotherapy Share. J Allied Health. 2006;35(2):109-15.

8. Camelo SHH, Angeram ELS. Professional competence: the building of concepts and strategies developed by health services and implications for nursing. Texto Contexto - Enfermagem. 2013;22(2): Jun.

9. Saeki K, Izumi H, Uza M, Murashima S. Factors Associated With the Professional Competencies of Public Health Nurses Employed by Local Government Agencies in Japan. Public Health Nurs. 2007;24(5):449-57.

10. Fouche C, Kenealy T, Mace J, Shaw J. Practictional perspectives from seven health professtional groups on core copetencies in the context of chronic care. Journaal of Interprofessional Care. 2014;28(6):534-40.

11. Lane IF. Professional competencies in health sciences education: from multiple intelligences to the clinic floor. Adv in Health Sci Educ. 2010:129-46.

12. Kavanagh $\mathrm{MH}$, Drennan L. What skills and attributes does an accounting graduate need? Evidence from student perceptions and employer expectations. Accounting \& Finance. 2008:279-3000.

13. EYF. Interns Revealed! A Survey on internship quality in Europe: European Youth Forum; 2011. Available from: "https://issuu.com/yomag/docs/yfj_internsrevealed_web". 
14. O'Higgins N, Pinedo L. Interns and outcomes: Just how effective are internships as a bridge to stable employment? International Labour Office. 2018 Aug 09.

15. Volpe Md. Assessment of internship effectiveness in South Italy Universities. Education + Training. 2017;59(7/8):797-810.

16. Anjum S. Impact of internship programs on professional and personal development of business students: a case study from Pakistan. Future Business Journal. 2020;6(2).

17. Gault J, Leach E, Duey M. Effects of Business Internships on Job Marketability: The Employer's Perspective. Education + Training. 2010;52(1):76-88.

18. Higher Education Statistics System (Arabic Content). Available from: https://hesc.moe.gov.sa/pages/default.aspx.

19. Te Pas E, Meinema JG, Visser MRM, van Dijk N. Blended learning in CME: the perception of GP trainers. EDUCATION FOR PRIMARY CARE. 2016;27(3):217-24.

20. Sharma P. Blended Learning. ELT Journal. 2010;64(4):456-8.

21. Nasir B, Jurd K, Cook S, Kwan M, Ostini R. Developing an Internship Preparedness Program for Final Year Medical Students. MedEdPublish. 2018.

22. SEU. Saudi Electronic University [Available from: http://www.seu.edu.sa].

\section{Tables}

Table 1: Distribution of interns at internship sites $N$ (\%)

\begin{tabular}{c|c|c|c|c|}
\multicolumn{5}{c}{ Internship Sites } \\
\hline \multirow{3}{*}{ Major } & Public & Private & Other & Total \\
\cline { 2 - 5 } Health Informatics & $53(70.67)$ & $4(5.33)$ & $18(24)$ & 75 \\
\cline { 2 - 5 } Public Health & $9(60)$ & $1(6.67)$ & $5(33.33)$ & 15 \\
\cline { 2 - 5 } Total & 62 & 5 & 23 & 90 \\
\cline { 2 - 5 } & & &
\end{tabular}

Table 2: Preceptors' evaluations of interns' performance 
Interpersonal Health Support Competencies

- Degree of independence

- Ability to conduct work activities without supervisions

- Effective oral and written communication with others

- Technical and professional competencies

Community Health Support Competencies

- Skills related to health specialty

Health Informatics

$$
N=81
$$

$$
N=15
$$

- Development of knowledge management tools

- Ability to coordinate several activities, ideas, and thoughts

- Awareness of work procedures

- Meeting role expectations

- Reporting to work on-time

- Appropriate reporting of schedule changing

- Conforming to the dress code

\section{Administrative Competencies}

- Preparing reports and written assignments that are free of errors

- Preparing reports and written assignments on time

- Ability to concentrate on work assignments until completion

- Ability to organize assignments effectively and efficiently

\section{Nontechnical Competencies}

- Degree of initiative

- Work-relations with coworkers

- Preservation of confidentiality and personal privacy of others

- Polite \& considerate speech and manners with others

- Maintaining clean and orderly work place

$\begin{array}{lll}4.72 & 5 & 0.514 \\ 4.78 & 5 & 0.412 \\ 4.79 & 5 & 0.431 \\ 4.79 & 5 & 0.455 \\ 4.82 & 5 & 0.456 \\ 4.74 & 5 & 0.484 \\ 4.85 & 5 & 0.408 \\ 4.84 & 5 & 0.363 \\ 4.94 & 5 & 0.282\end{array}$

\begin{tabular}{ccc}
4.59 & 5 & 0.622 \\
4.80 & 5 & 0.448 \\
4.93 & 5 & 0.260 \\
4.78 & 5 & 0.461 \\
Mean & Mode & SD \\
4.77 & 5 & 0.444 \\
4.92 & 5 & 0.312 \\
4.94 & 5 & 0.242 \\
4.91 & 5 & 0.291 \\
4.69 & 5 & 0.200 \\
4.84 & 5 & 0.363 \\
\hline
\end{tabular}




\section{Figures}

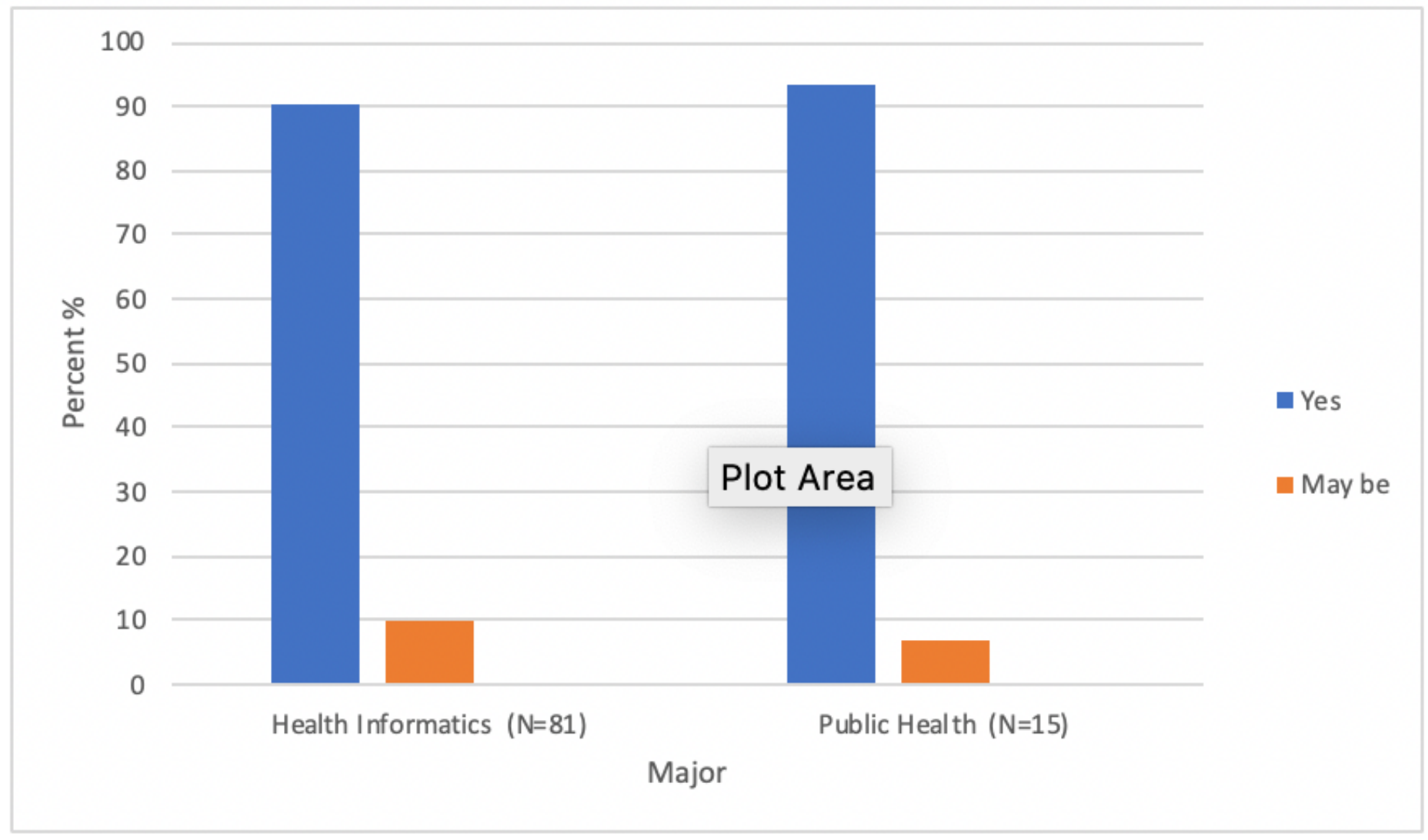

Figure 1

Community preceptors' opinions regarding hiring blended learning Health Sciences graduates, in percentage 